\title{
REVIEW
}

\section{Adrenal and ovarian autoimmunity}

\author{
C Betterle and M Volpato \\ Institute of Semeiotica Medica, Chair of Clinical Immunology and Allergy, University of Padova, Via Ospedale Civile 105, 35128 Padova, Italy
}

(Correspondence should be addressed to C Betterle)

\section{Autoimmune adrenal insufficiency}

Addison's disease, described first by Thomas Addison (1), is quite rare and has been described in 40-110 cases per 1000000 inhabitants (2-4). Currently, in the developed countries the most common cause of primary adrenal failure is autoimmunity, causing up to $75-80 \%$ of the cases of adrenal insufficiency, while tuberculosis is the second most frequent cause, responsible for up to $15-20 \%$ of the cases. Many other rare causes are involved in $5-7 \%$ of patients $(5,6)$. Consequently, autoimmune Addison's disease (AAD) can be considered as a synonym of the idiopathic form of adrenal failure.

About $50-60 \%$ of AAD patients have or develop during their life other autoimmune disorders; in the remaining cases the adrenal failure manifests itself as an isolated disease (7).

Four main types of polyglandular autoimmune disease (PGAD) have been classified by Neufeld \& Blizzard (8) and AAD is a fundamental disease of PGAD types 1 and 2 . AAD can present in three main clinical forms: (i) PGAD type 1, (ii) PGAD type 2, (iii) isolated $(9-11)$.

\section{PGAD type 1}

PGAD type 1 consists of chronic hypoparathyroidism, chronic candidiasis and AAD. PGAD type 1 has also been called autoimmune poly-endocrinopathy, candidiasis, ectodermal dystrophy (APECED) (12).

To define this syndrome, at least two of these major components need to be present $(8,13,14)$. The three main diseases occur, in general, in a fairly precise chronological order, and they are present all together only in one-third of the observations $(12,14,15)$. Candidiasis is usually the first manifestation to appear, mostly before the age of 5, followed by hypoparathyroidism, usually before the age of 10 , and later by Addison's disease, before the age of 15 . Thus, PGAD type 1 occurs for the most part in childhood and the complete evolution takes place in the first 20 years of life $(8,12,14,15)$. In addition, other minor components, often appearing later in life, can be present such as: (i) autoimmune endocrinopathies (hypergonadotropic hypogonadism, insulin-dependent diabetes mellitus, autoimmune thyroid diseases); (ii) autoimmune or immuno-mediated gastrointestinal diseases (chronic atropic gastritis, pernicious anemia, coeliac disease); (iii) chronic active hepatitis; (iv) autoimmune skin diseases (vitiligo, alopecia); (v) ectodermal dystropy; (vi) keratoconjunctivitis; (vii) immunological defects (T cell defect, IgA deficiency, asplenia) $(8,12-14,16)$. PGAD type 1 is a very rare disorder in the world except in Finland where, probably as a result of a funder gene effect, the estimated frequency is about $1 / 25000$ inhabitants. The ratio of females/males varied from 0.8 to 2.4 in the different studies $(8,12,14)$. PGAD type 1 is a condition occurring sporadically or among siblings (15-18). The mode of presentation argues for an autosomal recessive inheritance $(17,19)$. In the initial studies association with human leukocyte antigen (HLA)-A28 was found to be more frequent in patients with this syndrome than in normal controls, and association with HLA-A3 was more frequent in those with PGAD type 1 and ovarian failure than in those with normal ovarian function (20). A study of 14 Finnish families with PGAD type 1 has shown that the gene responsible for this condition is located on chromosome 21 (21). Recently, we found a high frequency of association with HLA-DR 5, with a relative risk of 2.85 (14).

\section{PGAD type 2}

PGAD type 2, also known as Schmidt's syndrome, is characterized by the constant presence of AAD and either thyroid autoimmune disease and/or insulindependent diabetes mellitus (IDDM) (7, 8, 13, 22, 23). In addition, other diseases may be present such as hypergonadotropic hypogonadism, vitiligo, alopecia, chronic atropic gastritis with or without pernicious anemia, and hypophysitis (13).

IDDM, when present, develops before Addison's disease, whereas thyroid autoimmune disease can develop before, contemporary with or after adrenal insufficiency $(7,23)$. PGAD type 2 occurs in about $15-$ 45 cases per 1000000 inhabitants, at all ages and in both sexes, but it is most common in middle-aged females $(7,11)$. PGAD type 2 most often occurs in many generations of the same family, and shows a pattern of inheritance consistent with autosomal 
dominance and incomplete penetrance. HLA-DR3 and/ or -DR4 were found to be increased in an American series of patients with PGAD type 2 with or without IDDM (24). In two groups of patients from Germany and the United Kingdom, only the increased prevalence of HLA-DR 3 was confirmed $(25,26)$. Recently, we demonstrated an increased prevalence of HLA-DR3 and -DR 5 in an Italian population, HLA-DR3 was prevalent in PGAD type 2 patients with IDDM and HLA-DR 5 in those with thyroid autoimmunity (7). Particular polymorphic alleles corresponding to noncharged (non-Asp) amino acids at position 57 of the HLA DQb-chain have been found in IDDM patients with Addison's disease. Thus, the presence of nonaspartic amino acids at codon 57 of the DQb-chain may be a molecular marker of future IDDM in patients suffering from AAD $(25,26)$. These observations suggest that IDDM and AAD may have different genetic markers.

\section{Isolated AAD}

The third modality of presentation of AAD is the isolated form; in many patients apparently isolated clinical adrenal insufficiency is associated with the presence of one or more organ-specific autoantibodies in addition to adrenal cortex autoantibodies. For example, thyroid autoantibodies are present in $41 \%$, gastric parietal cell antibodies in $25 \%$, and islet-cell autoantibodies in $8 \%$ of the cases. These patients can be considered as affected by latent PGAD type 2 . In some cases, they will develop clinical thyroid diseases, IDDM or chronic atropic gastritis (7). Therefore, the truly isolated AAD is quite rare. In clinically isolated $\mathrm{AAD}$ an increased frequency of HLA-DR3 was found $(25,26)$.

\section{Pathology}

The adrenal glands from AAD patients are reduced in weight. In the active phase of the disease there is a widespread but variable mononuclear cell infiltrate consisting of lymphocytes, plasma cells and macrophages. Residual cortical nodules can be seen as the disease progresses, but these are eventually destroyed and the cortex is replaced by fibrous tissue $(27,28)$.

\section{Adrenal-cortex autoantibodies and autoantigens}

\section{Adrenal-cortex autoantibodies in patients with clinical AAD}

Adrenal-cortex autoantibodies (ACA) were first demonstrated by a complement-fixation test (29) and later by the indirect immunofluorescence technique using cryostat sections of human adrenal-cortex glands (30). These techniques allowed the detection of ACA in $36-60 \%$ of patients with AAD but also in $7-10 \%$ of those with tuberculosis, as reviewed by Betterle et al. (6). The frequency of ACA varied according to the methods employed, the substrate used, the heterogeneity of the patients, the sex, the age at onset, the duration of the disease, and the presence of other autoimmune endocrine diseases. Furthermore, difficulties in the correct diagnosis of Addison's disease may also have contributed to reduce the frequency of ACA in patients with $\mathrm{AAD}$ and to increase it in those with tuberculosis (6). Using indirect immunofluorescence and beef adrenal cortex, ACA were detected in $87 \%$ of patients with $\mathrm{AAD}$ and in $0 \%$ of those with tuberculosis, in $92 \%$ of those who had had AAD for less than 3 years and in $61 \%$ of those with longer-standing disease (6). Furthermore, according to the different forms of AAD, ACA were found in $90 \%$ of patients with PGAD type 1, in 94\% of those with PGAD type 2, and in $63 \%$ of the isolated cases $(6,7)$. These data suggest that adrenal insufficiency in the context of the PGADs is autoimmune in origin with ACA virtually positive in all the cases. With regard to isolated adrenal insufficiency, the absence of ACA is highly suspect in forms of non-autoimmune origin.

\section{ACA in patients without clinical AAD}

ACA have also been found in subjects without clinical AAD with a prevalence varying from $0.3 \%$ in patients with vitiligo to $48 \%$ in those with idiopathic hypoparathyroidism $(31,32)$. It has been shown that the presence of complement-fixing ACA is a marker for a high risk of progression to clinical AAD (33). The natural history of AAD progresses through 4 different stages of adrenal cortex hypofunction; in stage 1 , an increase in plasma renin activity is associated with a normal or low serum aldosterone level, which suggests that, initially, the zona glomerulosa is affected. After several months or years, a dysfunction of the zona fasciculata becomes evident which is manifested at first by a decrease of the plasma cortisol response to adrenocorticotropic hormone (ACTH) (stage 2), followed by an increased plasma ACTH level (stage 3) and finally by a decreased plasma cortisol level and overt clinical symptoms (stage 4) (34). Subsequently, it has been reported that ACA in some patients without clinical AAD can disappear spontaneously or after corticosteroid therapy with restoration of the previous impaired adrenal function (35). However, recent follow-up studies of 58 ACA-positive patients (children and adults) indicated that ACA were persistent markers of progression towards overt or subclinical AAD $(31,32)$. The risk of progression to AAD was high in the group of ACA-positive children (cumulative risk of $100 \%$ at 11 years) (32) compared with a lower risk in the group of ACA-positive adults (cumulative risk of $31.6 \%$ at 11 years) (31). In the case of ACA-positive adults the presence of a high 
titer of antibodies and HLA-DR3 were additional risk factors for clinical AAD (31).

\section{Steroid-producing cells autoantibodies}

In addition to ACA, some of the patients showed a reaction with cytoplasmic antigens common to other steroid-producing cells such as Leydig cells of the testis, theca cells of the ovary and syncytiotrophoblasts of the placenta. These antibodies are called steroid-producing cells autoantibodies (36). There is a strong association between steroid cell autoantibodies and ACA, and the former can only be detected in the presence of ACA. Steroid cell autoantibodies are polyclonal IgGs that can be distinguished from ACA by preabsorption tests with homogenates of any of the steroid-producing target organs which remove steroid cell autoantibodies reactivity, whereas ACA recognize exclusively the adrenal gland (37). The prevalence of steroid cell autoantibodies varied in different studies and in ACApositive patients with AAD they were found in $26 \%$ of the women and $4 \%$ of the men (38), compared with $60-100 \%$ of patients with PGAD type $1,25-40 \%$ of patients with PGAD type 2 and $18 \%$ of patients with isolated $\operatorname{AAD}(6,7,11,39)$. The presence of steroid cell autoantibodies generally correlated with the presence of primary gonadal failure (hypergonadotropic hypogonadism) $(7,39,40-42)$. The high prevalence of steroid cell autoantibodies in PGAD type 1 presumably explains why gonadal failure more frequently occurs in patients with this syndrome compared with those with PGAD type 2 (10). In female patients without gonadal failure, the presence of steroid cell autoantibodies confers a high risk of progression towards clinical hypergonadotropic gonadal failure (predictive value $30 \%)(43,44)$.

\section{ACTH-receptor autoantibodies}

Some autoantibodies have the ability to bind to the cell receptor and affect their function either through mimicking normal ligand action or blocking the ligand binding site on the receptor as reviewed by Wilkin (45). Serum IgG fraction from a woman with $\mathrm{AAD}$ was reported to block the ACTH-induced release of cortisol from guinea pig adrenal cells in vitro. This study suggested that adrenal cortex cell function could be diminished as a result of autoantibody binding to the ACTH receptor (46). IgGs capable of inhibiting both ACTH-induced adrenal DNA synthesis and cortisol production by guinea pig adrenal segments were reported in over $90 \%$ of the patients with clinical AAD (47). However, a subsequent study performed on guinea pig adrenal cells did not confirm these results, and the inhibitory effects seemed most likely to be attributable to the effects of non-IgG components of the IgG preparations (48). At present, the existence of ACTH receptor-blocking autoantibodies is still under discussion and needs further investigation.

\section{Adrenal autoantigens}

Investigations on target autoantigens in AAD were initiated by the identification of a microsomal antigen of $55 \mathrm{kDa}$ (49). This was followed, in 1992, by the identification, independently in two laboratories, of steroid 21-hydroxylase $(21-\mathrm{OH})$ as a major adrenal autoantigen (50-52). In the same year screening of a human fetal adrenal cDNA library with the sera from patients with $\mathrm{AAD}$ in the context of PGAD type 1 allowed isolation of clones with high homology to steroid $17 \alpha$-hydroxylase $(17 \alpha-\mathrm{OH})$ and this study indicated that $17 \alpha-\mathrm{OH}$ was an autoantigen associated with the AAD in the context of PGAD type 1 (53). Reactivity of sera from patients with PGAD type 1 with cytochrome $\mathrm{P} 450$ side chain cleavage enzyme (P450scc) was reported soon afterwards (52). Reports on identification of $21-\mathrm{OH}$ as a major adrenal autoantigen were confirmed by studies in several laboratories using different methods, including Western blotting or immunoprecipitation analyses based on native or recombinant 21-OH expressed in bacteria, yeast, mammalian cells or in vitro transcription/translation system (54-57). In addition, recent studies have shown that $21-\mathrm{OH}$ is the major adrenal autoantigen in AAD irrespective of whether the disease presents as isolated AAD or PGAD type 1 or type 2 or in ACA-positive patients without overt AAD $(58,59)$. Furthermore, a good agreement between the results of ACA (measured by indirect immunofluorescence) and 21-OH autoantibodies (Abs) indicates that 21-OH Abs are the major component of the ACA (56-60). Consequently, 21-OH/ ACA have been shown to be markers of progression towards overt AAD in ACA-positive adults and children as described above (31-32).

There were, however, some discrepancies in the different studies regarding the reactivity and the prevalence of autoantibodies to $17 \alpha-\mathrm{OH}$ and $\mathrm{P} 450 \mathrm{scc}$ in patients with PGAD type 1, type 2 or isolated AAD $(52,53,55,57,58,61)$. The reasons for these differences could be related, at least in part, to the sources of autoantigens used to detect autoantibodies (62). A recent study by Chen et al. showed that $17 \alpha-\mathrm{OH}$ and P450scc Abs in patients with PGAD type 1, type 2, isolated $\mathrm{AAD}$, and $\mathrm{ACA}$-positive patients without overt AAD were found at prevalences lower than 21$\mathrm{OH}$ Abs (58). Furthermore, 32/33 sera (97\%) which were positive for $17 \alpha-\mathrm{OH}$ and/or $\mathrm{P} 450 \mathrm{scc}$ Abs were also positive for 21-OH Abs. Following comparison with steroid cell autoantibodies, $17 \alpha-\mathrm{OH}$ and P450scc appear to be the major components of steroid cell autoantibodies measured by indirect immunofluorescence (58). Reactivity against other steroidogenic enzymes has been studied but none of the sera from patients with AAD was found to react with $11 \beta$-hydroxylase $(11 \beta-\mathrm{OH})$ and $3 \beta$-hydroxysteroid dehydrogenase $(3 \beta$-HSD) $(54,57,63)$, aromatase and adrenodoxin (57). 
Studies relating to the autoepitopes recognized on 21-OH by sera from patients with AAD were performed by Western blot analysis using 21-OH expressed in an in vitro transcription/translation system, in bacteria or yeast: $90 \%$ of the sera reacted with the central portion (residues 165-379) of the protein and the majority of them identified an epitope located between residues 281-379, where the proposed steroid binding site is located $(54,64,65)$. Furthermore, half of the sera reacted with the central and C-terminal portion (residues 380-494). Also, 21-OH Abs reacted in a markedly weaker fashion with $21-\mathrm{OH}$ containing amino acid mutations within the central and the C-terminal, regions, which are associated with diminished 21-OH enzyme activity $(59,65)$. Overall, studies using modified 21-OH proteins containing amino acid deletions or single amino acid mutations indicate that autoantibody epitopes on human 21-OH are conformational and are formed by central and C-terminal parts of the molecule and suggest a close relationship between 21-OH amino acid sequences important for 21-OH enzyme activity and the autoantigen binding site(s). The study of the patients with different forms of AAD, either isolated or in the context of PGAD types 1 and 2 or with subclinical or potential $\mathrm{AAD}$, confirmed these observations and did not demonstrate significant differences between the epitopes recognized by $21-\mathrm{OH}$ Abs in different patient groups (66).

\section{Enzymes and corresponding auto- antibodies in the pathophysiology of AAD and other autoimmune diseases}

The three enzymes recently recognized as target autoantigens in AAD are members of the cytochrome P450 family, which is located in the endoplasmic reticulum; its activity depends on NADPH cytochrome $\mathrm{P} 450$ reductase, which is not expressed on the cell surface. Of the three enzymes, only $21-\mathrm{OH}$ is adrenalspecific, $17 \alpha-\mathrm{OH}$ being expressed in adrenals and in gonads, and $\mathrm{P} 450 \mathrm{scc}$ is present in adrenals, gonads and placenta. These enzymes are involved in the synthetic pathway of glucocorticoids, mineralocorticoids and sex hormones $(28,60,67)$. The zona glomerulosa is the major source of mineralocorticoids, the zona fasciculata and the zona reticularis are thought to act as a functional unit in the production of cortisol and androgens (28).

The demonstration that steroidogenic enzymes are target autoantigens in AAD supported the hypothesis of a role of these autoantibodies in the pathogenesis of the disease. An in vitro study demonstrated that IgGs from patients with $\mathrm{AAD}$ and antibodies to 21-OH were able to inhibit 21-OH enzyme activity (68). In an attempt to confirm these data in vivo, patients with antibodies to 21-OH and clinical or subclinical AAD were stimulated with ACTH i.v., but no increment of 17-hydroxyprogesterone was found, indicating a lack of the inhibiting effect of these autoantibodies in vivo (69). This may be consistent with the report that the passive transfer of IgG from the pregnant mother with $\mathrm{AAD}$ to the fetus has never been shown to induce a transient hypoadrenalism.

\section{New tests for adrenal autoantibodies}

ACA have been detected by indirect immunofluorescence using different animal and human adrenal cortex sections, and by ELISA and RIA methods using adrenal microsomes. However, only the indirect immunofluorescence has been a reliable technique for many years, as reviewed by Betterle et al. (6). Recently, the laboratory diagnosis of AAD has been enriched by use of specific recombinant autoantigens. Two different immunoprecipitation assays for the detection of autoantibodies to 21-OH (21-OH Abs) have been developed, one based on ${ }^{35}$ S-labeled $21-\mathrm{OH}$ produced in an in vitro transcriptiontranslation system $(56,70)$, the other based on ${ }^{125} \mathrm{I}$ labeled recombinant $21-\mathrm{OH}$ produced in yeast (59). Immunoprecipitation assays based on ${ }^{35} \mathrm{~S}-21-\mathrm{OH}$ are highly specific and sensitive with a good reproducibility but there are limitations associated with the use of DNA and ${ }^{35}$ S-labeled material. Assays based on 21-OH labeled with ${ }^{125} \mathrm{I}$, however, in addition to high specificity, sensitivity and a good precision have the added advantage of being convenient and easy to use in routine laboratories. There is a good agreement between results of 21-OH Abs in these assays and ACA by indirect immunofluorescence $(56,58,59)$. In contrast, Falorni et al. found some discrepancies between 21-OH Abs and ACA (71). The reasons for these discrepancies are not clear at present but may be related to technical aspects of autoantibodies assays, in particular the indirect immunofluorescence test, which require considerable experience, great care and stringent control procedures to be observed.

To avoid discrepancies in adrenal autoantibodies measurements, an international standardization and proficiency program should be performed in the near future, similar to that successfully performed for isletcell autoantibodies (72-74).

\section{Cellular immunity}

In the last few years, very little progress has been made in the understanding of the precise cellular mechanisms leading to AAD. Evidence for an antigenspecific T-lymphocyte response comes from early studies of migration inhibition tests using adrenal cortex antigens $(75,76)$. Furthermore, a non-specific reduction of the suppressor T-lymphocyte function has been demonstrated $(77,78)$. The study of the peripheral cells demonstrated an increased percentage of activated T-lymphocytes in patients with recent onset disease 
compared with those with longstanding AAD (79). More recently, a proliferative T-cell response to a fraction with molecular weight of $18-24 \mathrm{kDa}$ has been demonstrated (80).

In an animal model, transfer of spleen cells from mice immunized with adrenal extracts led both to the development of adrenal cortex infiltrates and autoantibodies in healthy recipients but without development of adrenal insufficiency (81). Studies of human adrenocortical tissue from patients with AAD, with characterization of the infiltrating cells, their isolation and cloning, should allow the identification of T-cells autoepitopes and the further progression in our understanding of the cellular mechanisms involved in this disease.

\section{Gonadal insufficiency}

\section{Definition}

Premature ovarian failure (POF) is defined as the cessation of ovarian function after puberty and before the age of 40. POF implies that the ovaries have undergone differentiation and have functioned but their function has failed before the expected time of menopause. So, the typical presentation is as secondary amenorrhea but, in rare cases, it can also be as primary amenorrhea (82). The prevalence of POF is found in $0.2 \%$ of the female population and an autoimmune origin represents approximately $20 \%$ of all cases $(11,83)$.

\section{Autoimmune POF}

The diagnosis of autoimmune POF is quite difficult and is based mainly on the exclusion of the other known causes and the demonstration of one or more of the criteria for autoimmune diseases. Two distinct entities are identifiable: (i) autoimmune oophoritis and (ii) resistent ovary syndrome, also called Savage's syndrome (84).

Genetic assessment has been performed in a group of Caucasian females with isolated secondary amenorrhea without autoantibodies or autoimmune diseases and has allowed the demonstration of HLA-B35 in $37 \%$ of the cases with a relative risk of 2.99 , and HLA-DR 3 in $53 \%$ of the cases with a relative risk of 4.3 (85).

Autoimmune POF can present in the following forms: (i) associated with $\mathrm{AAD}$ or adrenal cortex autoantibodies and (ii) isolated or associated with autoimmune diseases other than AAD $(44,86)$.

\section{POF associated with AAD}

The association between clinical AAD and POF was documented many years ago when POF was reported in $6 / 77(8 \%)$ patients with AAD; 5 of the $6(83 \%)$ were steroid cell autoantibodies-positive (40). Subsequently, it has been observed that the prevalence of POF ranged from $17 \%$ to $50 \%$ in patients with PGAD type $1(8,12)$ and from $3.6 \%$ to $7 \%$ in those with PGAD type $2(7)$.

The histological descriptions of the ovaries from these patients are rare, and those reported are based mainly on observations obtained on scarce biopsy material. Oophoritis at biopsy was documented in $18 / 18$ patients with POF and AAD (40, 87-96). Autoimmune oophoritis is characterized by lymphocytic and plasma cell infiltration of the endocrine hilar cells, theca interna of growing follicles and corpora lutea. In the majority of the cases there is a lack of ovarian follicles and sometimes the glands appear fibrotic (streak ovaries) $(16,38,90)$. Immunohistochemical analysis of the lymphocytic oophoritis reveals that the inflammatory cells consist mainly of T-lymphocytes (CD4+ and $\mathrm{CD} 8+$ ), a few B cells with a large number of plasma cells, macrophages and NK cells (91). These data underline the close relationship between AAD and autoimmune POF due to oophoritis.

Autoantibodies and autoantigens All the patients with POF associated with AAD are steroid cell autoantibodies-positive $(7,37,39,40,44)$. In general, POF follows AAD in patients with PGAD type 1 and precedes it in those with PGAD type 2 (44). Steroid cell autoantibodies have also been found in $20-34 \%$ of AAD patients in the absence of POF $(38,39,44)$. The followup of these patients revealed a high risk of gonadal failure in females but not in males $(43,44)$. Furthermore, steroid cell autoantibodies have also been found in $7.3 \%$ of patients with POF without AAD (44) and these patients have a high risk of development of clinical $\operatorname{AAD}(31,32)$.

Sera from fifteen patients with POF in the context of PGAD type 1 were studied by immunoblotting: $60 \%$ reacted with $\mathrm{P} 450 \mathrm{scc}, 40 \%$ with $17 \alpha-\mathrm{OH}$, and only $33 \%$ with $21-\mathrm{OH}$ (55). These data were subsequently confirmed by immunoprecipitation studies (57). Winqvist et al. (97) using Western blot, studied sera from patients with AAD reacting with Leydig cells and found that the steroid cell antigen consisted mainly of P450scc (in $80 \%$ of the sera), and a $51 \mathrm{kDa}$ protein of unknown function (in $60 \%$ of the sera); 21 $\mathrm{OH}$ was recognised by only $40 \%$ of the sera. We studied, by immunoprecipitation assay, 26 steroid cell autoantibodies-positive patients with clinical or subclinical AAD, 11 of whom had POF, and found that 26/ $26(100 \%)$ of the steroid cell autoantibodies-positive sera reacted with $21-\mathrm{OH}, 16 / 26(61.5 \%)$ with $17 \alpha-\mathrm{OH}$ and $17 / 26(65 \%)$ with P450scc (58). Again, in this group of patients a good correlation was found between ACA and 21-OH and between steroid cell autoantibodies and $17 \alpha-\mathrm{OH}$ and/or P450scc. The differences in reactivity to steroidogenic enzymes among POF patients could be due to the different origin of the patients; however they indicate the 
necessity of standardization and proficiency programs as suggested in the case of 21-OH Abs.

\section{POF isolated or associated with autoimmune diseases other than $A A D$}

Besides AAD, numerous other autoimmune diseases, both endocrine and non-endocrine, frequently occur in association with POF. They include autoimmune thyroid diseases, myasthenia gravis, chronic candidiasis, hypoparathyroidism, vitiligo, alopecia, diabetes mellitus, idiopathic thrombocytopenic purpura, autoimmune hemolytic anemia, pernicious anemia, hypophysitis, Crohn's diseases, Sjögren's syndrome, primary biliary cirrhosis, chronic active hepatitis, malabsorption, systemic lupus erythematosus, and rheumatoid arthritis (98). A second autoimmune disorder is present in $10-39 \%$ of patients with POF, in the majority at a subclinical level $(44,86,99,100)$.

Lymphocytic oophoritis is an exceptional finding in these patients as it has been described in only 6/198 patients with POF not associated with AAD, while in the majority, follicular activity without evidence of lymphocytic infiltration was found (95, 101-116). These data indicate that the absence of lymphocytic oophoritis cannot be regarded as conclusive evidence against an autoimmune aetiology, as this could equally be due to immunological mechanisms, such as blocking antibodies hypothesized for Savage's syndrome. This syndrome is characterized by amenorrhea in association with hypergonadotropism and apparently normal ovarian follicular apparatus with immature follicles (84).

Autoantibodies and autoantigens Steroid cell autoantibodies are very rare in sera from patients with POF without $\operatorname{AAD}(39,44)$. Recently, many other autoantibodies to gonads have been detected by ELISA in patients with POF isolated or associated with autoimmune diseases excluding AAD. Using corpora lutea extracts, autoantibodies binding protein complexes of $2-36 \mathrm{kDa}$ and $70 \mathrm{kDa}$ have been demonstrated, the latter possibly corresponding to the unoccupied receptor for luteinizing hormone/human chorionic gonadotropin (LH/hCG) (117). These antibodies were present in patients with primary or secondary sterility with or without endometriosis (117). However, the presence of these was not confirmed in various types of POF in another study (118). Autoantibodies to either ovary or oocytes were detected in $66 \%$ of patients with POF alone, in $75 \%$ of POF associated with other autoimmune disorders, and in $78 \%$ of POF with previous pelvic surgery (119). Using two different preparations of human ovarian antigens, reactivity was found in $24 \%$ and $60 \%$ of the patients with various types of POF (iatrogenic POF, Turner's syndrome, idiopathic POF and POF associated with AAD) and a frequent crossreactivity to fallopian tube antigens was also found
(118). These results suggest that ovarian antibodies are common in POF, but their specificity and pathogenic role are questionable. Recently, an antibody to $3 \beta$-HSD was found in $10 / 48(21 \%)$ POF patients without other autoimmune diseases, all except one were steroid cell autoantibodies-negative (63).

Follicle-stimulating hormone $(\mathrm{FSH})$ receptor-blocking antibodies were first identified in 3 patients with myasthenia gravis complicated by amenorrhea due to gonadotropin-resistant ovary syndrome as documented by the presence of high levels of gonadotropin and numerous cortical primordial follicles at biopsy (120, 121). A common immunological mechanism mediated by blocking antibodies to acetylcholine receptors and against FSH receptors was hypothesized in these two diseases. Using Feulgen's cytochemical bioassay, IgGs capable of blocking FSH-induced granulosa cell DNA synthesis were demonstrated in 21/26 (81\%) women with POF (14/15 with Savage's syndrome and 7/11 with isolated POF) (122). Subsequently, a mouse adrenal cell line transfected with human recombinant gonadotropin receptor genes was employed for studying the effects of IgG from patients with POF on progesterone production and cAMP responses. No blocking effects were demonstrated in this experiment (123). Thus, antibodies against $\mathrm{LH}$ and FSH receptors may exist but their precise role and prevalence require further studies, including use of cells transfected with recombinant human receptors.

The involvement of $\mathrm{T}$ cells in human oophoritis was suggested when migration inhibitory factor production towards ovarian and testicular tissue was found in the serum from a patient with thyroiditis, adrenalitis and POF (124). CD4/CD8 ratios have been found to be decreased, increased or normal (86). It was demonstrated that circulating activated T-lymphocytes were increased in patients with POF $(11,90,125,126)$, this increment was partially reduced under estrogen substitution indicating that the endocrine defect can contribute to this phenomenon (11). Recently, the number of T-cell subsets have also been found to be in the normal range in POF with elevated FSH levels (127). As yet, no consistent pattern of cell-mediated immunity in POF has emerged from studies in vitro.

\section{Concluding remarks}

Autoimmune Addison's disease can present in various forms. Adrenal-cortex autoantibodies are found in the majority of these patients and 21-OH Abs appear to be the major component of these antibodies irrespective of whether the disease presents as isolated AAD or PGAD type 1 or type 2 or potential or subclinical AAD. There is a good agreement between the results of ACA (measured by indirect immunofluorescence) and 21-OH Abs (by immunoprecipitation assays). Furthermore, $17 \alpha$ $\mathrm{OH}$ and $\mathrm{P} 450 \mathrm{scc}$ appear to be the major components of steroid cell autoantibodies and are correlated with the presence of POF. 
An international standardization and proficiency program should be performed in the near future for adrenal autoantibodies measurements, similar to that successfully performed for other main autoantibodies.

\section{Acknowledgements}

We acknowledge the help of Dr Jadwiga Furmaniak in the revision of the manuscript.

\section{References}

1 Addison T. (1855). On the constitutional and local effects of disease of the suprarenal capsules. In a collection of the published writing of the late Thomas Addison, M.D., physician to Guy's Hospital. London: New Sydenham Society 1868. Reprinted in Medical Classics 19372 244-293.

2 Stuart-Mason A, Meade TW, Lee JAH \& Morris JN. Epidemiological and clinical picture of Addison's disease. Lancet 19682 744-747.

3 Nerup J. Addison's disease - clinical studies. A report of 108 cases. Acta Endocrinologica 197476 127-141.

4 Kong MF \& Jeffcoate W. Eighty-six cases of Addison's disease. Clinical Endocrinology 199441 757-761.

5 Kannan CR. Addison's disease. In The Adrenal Gland, pp 31-96. Ed CR Kannan. London: Plenum Medical Book Company, 1988.

6 Betterle C. Pedini B \& Presotto F. Serological markers in Addison's disease. In Advances in Thomas Addison's Diseases, vol 2, pp 67-84. Eds R Bhatt, VHT James, GM Besser, GF Bottazzo \& H Keen. Bristol: Journal of Endocrinology Ltd, 1994.

7 Betterle C, Volpato M, Greggio AN \& Presotto F. Type 2 polyglandular autoimmune disease. Journal of Pediatric Endocrinology and Metabolism 19969 113-123.

8 Neufeld M \& Blizzard RM. Polyglandular autoimmune diseases. In Symposium on Autoimmune Aspects of Endocrine Disorders, pp 357-365. Eds A Pinchera, D Doniach, GF Fenzi \& L Baschieri. New York: Academic Press, 1980.

9 Orth DN, Kovacs WJ \& DeBold CR. The adrenal cortex. In Williams Textbook of Endocrinology, edition 8, pp 489-619. Eds JD Wilson \& DW Foster. Philadelphia: WB Saunders, 1992.

10 Anonymous. Enzymes as autoantigens (Editorial). Lancet 1992 $339779-780$.

11 Bottazzo GF, Mirakian R \& Drexhage HA. Adrenalitis, oophoritis and autoimmune polyglandular disease. In Clinical Immunology. Principles and Practice, ch 100, pp 1523-1536. Eds RR Rich, TA Fleisher, DB Schwartz, WT Shearer and W Strober. St Louis: Mosby, 1996.

12 Ahonen P, Myllarniemi S, Sipila I \& Perheentupa J. Clinical variation of autoimmune polyendocrinopathy-candidiasis-ectodermal dystrophy (APECED) in a series of 68 patients. New England Journal of Medicine 1990322 1829-1836.

13 Doniach D \& Bottazzo GF. Polyendocrine autoimmunity. In Clinical Immunology Update, pp 95-121. Ed EC Franklin. Amsterdam: Elsevier North Holland, 1981.

14 Betterle C, Greggio NA \& Volpato M. Polyglandular autoimmune disease type 1 . Clinical, immunological and genetic study on an Italian series of 41 patients. Journal of Clinical Endocrinology and Metabolism 1998 (In Press).

15 Brun JM. Juvenile autoimmune polyendocrinopathy. Hormone Research $198216308-316$.

16 McIntyre Gass JD. The syndrome of keratocojunctivitis, superficial moniliasis, idiopathic hypothyroidism and Addison's disease. American Journal of Ophthalmology 196254 660-674.

17 Spinner MW, Blizzard RM \& Childs B. Clinical and heterogeneity in idiopathic Addison's disease and hypoparathyroidism. Journal of Clinical Endocrinology 196828 795-804.

18 Wirfalt A. Genetic heterogeneity in autoimmune polyglandular failure. Acta Medica Scandinavica 1981210 7-13.
19 Ahonen P. Autoimmune polyendocrinopathy-candidosis-ectodermal dystrophy (APECED): autosomal recessive inheritance. Clinical Genetics 198527 535-542.

20 Ahonen P, Koskimies S, Lokki ML, Tiilikainen A \& Perheentupa Y. The expression of autoimmune polyglandular disease type I appears associated with several HLA-A antigens but not with HLA-DR*. Journal of Clinical Endocrinology and Metabolism 1988 66 1152-1157.

21 Aaltonen J, Bjorses P, Sandkuijl L, Perheentupa J \& Peltonen L. An autosomal locus causing autoimmune disease: autoimmune polyglandular disease type I assigned to chromosome 21. Nature Genetics 19948 83-87.

22 Schmidt MB. Eine biglanduläre Erkrankung (Nebennieren und Schilddrüse) bei Morbus Addisonii. Verhandlungen der Deutschen Gesellschaft für Pathologie 192621 212-221.

23 Papadopoulos IK \& Hallengren B. Polyglandular autoimmune syndrome type II in patients with idiopathic Addison's disease. Acta Endocrinologica 1990122 472-478.

24 Maclaren NK \& Riley WJ. Inherited susceptibility to autoimmune Addison's disease is linked to human leukocyte antigen-DR3 and/or -DR4, except when associated with type 1 autoimmune polyendocrine syndrome. Journal of Clinical Endocrinology and Metabolism 198662 455-459.

25 Böehm BO, Maufras B, Seidl S, Holzberger G, Kuhnl P \& Rosak C. The HLA-DQbeta non-Asp-57 allele: a predictor of future insulin-dependent diabetes mellitus in patients with autoimmune Addison's disease. Tissue Antigens 199137 130-132.

26 Weetman AP, Zhang L, Tandon N \& Edwards OM. HLA associations with autoimmune Addison's disease. Tissue Antigens 199138 31-33.

27 McNicol AM. Histopathology of the adrenal gland in Addison's disease. In Advances in Thomas Addison's Diseases, vol 2, pp 5-11. Eds R Bhatt, VHT James, GM Besser, GF Bottazzo \& H Keen. Bristol: Journal of Endocrinology Ltd, 1994.

28 McNicol AM \& Laidler P. The adrenal glands and extra-adrenal paraganglia. In Endocrine System, pp 59-121. Ed PD Lewis. Edinburgh, UK: Churchill Livingstone, 1996.

29 Anderson JR, Goudie RB, Gray KG \& Timbury GC. Autoantibodies in Addison's disease. Lancet 1957 i 1123-1124.

30 Blizzard RM, Chandler RW, Kyle MA \& Hung W. Adrenal antibodies in Addison's disease. Lancet 1962 ii 901-903.

31 Betterle C, Volpato M, Rees Smith B, Furmaniak J, Chen S, Greggio NA et al. I. Adrenal cortex and steroid 21-hydroxylase autoantibodies in adult patients with organ-specific autoimmune diseases: markers of low progression to clinical Addison's disease. Journal of Clinical Endocrinology and Metabolism 199782 935-938.

32 Betterle C, Volpato M, Rees Smith B, Furmaniak J, Chen S, Zanchetta R et al. II. Adrenal cortex and steroid 21-hydroxylase autoantibodies in children with organ-specific autoimmune diseases: markers of high progression to clinical Addison's disease. Journal of Clinical Endocrinology and Metabolism 199782 939-942.

33 Betterle C, Zanchetta R, Trevisan A, Zanette F, Pedini B, Mantero $\mathrm{F}$ et al. Complement-fixing adrenal autoantibodies as a marker for predicting onset of idiopathic Addison's disease. Lancet 1983 i $1238-1240$

34 Betterle C, Scalici C, Presotto F, Pedini B, Moro L, Rigon F et al. The natural history of adrenal function in autoimmune patients with adrenal autoantibodies. Journal of Endocrinology 1988117 $467-475$

35 De Bellis A, Bizzarro A, Rossi R, Amoresano Paglionico V, Criscuolo T, Lombardi G et al. Remission of subclinical adrenocortical failure in subjects with adrenal autoantibodies. Journal of Clinical Endocrinology and Metabolism 199376 10021007.

36 Anderson JU, Goudie RB, Gray \& Stuart-Smith DA. Immunological features of idiopathic Addison's disease: an antibody to cells producing steroid hormones. Clinical and Experimental Immunology 19683 107-117. 
37 Elder M, Maclaren N \& Riley W. Gonadal autoantibodies in patients with hypogonadism and/or Addison's disease. Journal of Clinical Endocrinology and Metabolism 198152 1137-1142.

38 Irvine WJ \& Barnes EW. Addison's disease, ovarian failure and hypoparathyroidism. Clinics in Endocrinology and Metabolism $19754379-434$

39 Sotsiou F, Bottazzo GF \& Doniach D. Immunofluorescence studies on autoantibodies to steroid-producing cells, and to germline cells in endocrine disease and infertility. Clinical and Experimental Immunology 198039 97-111.

40 Irvine WJ, Chan MMW \& Scarth L. Immunological aspects of premature ovarian failure associated with idiopathic Addison's disease. Lancet 1968 ii 886-887.

41 Weetman AP. Autoimmunity to steroid-producing cells and familial polyendocrine autoimmunity. In Baillière's Clinical Endocrinology and Metabolism, vol 9, pp 157-174. London: Baillière Tindall, 1995.

42 Betterle C, Volpato M, Pedini B, Chen S, Furmaniak J \& Rees Smith B. Adrenal-cortex and 21-hydroxylase autoantibodies in autoimmune Addison's disease. Journal of Endocrinological Investigation 199720 (Suppl 4) 91.

43 Ahonen P, Miettinen A \& Perheentupa J. Adrenal and steroidal cell antibodies in patients with autoimmune polyglandular disease type I and risk of adrenocortical and ovarian failure. Journal of Clinical Endocrinology and Metabolism 198764 494500.

44 Betterle C, Rossi A, Dalla Pria S, Artifoni A, Pedini B, Gavasso S et al. Premature ovarian failure: autoimmunity and natural history. Clinical Endocrinology 199339 35-43.

45 Wilkin TJ. Review article. Mechanisms of disease. Receptor autoimmunity in endocrine disorders. New England Journal of Medicine 19908 1318-1324.

46 Kendall-Taylor P, Lambert A, Mitchell R \& Robertson WR. Antibody that blocks stimulation of cortisol secretion by adrenocorticotrophic hormone in Addison's disease. British Medical Journal 1988296 1489-1491.

47 Wulffraat NM, Drexhage HA, Bottazzo GF, Wiersinga WM, Jencken P \& Van der Gaag R. Immunoglobulins of patients with idiopathic Addison's disease block the in vitro action of adrenocorticotropin. Journal of Clinical Endocrinology and Metabolism $198969231-238$.

48 Wardle CA, Weetman AP, Mitchell R, Peers N \& Robertson WR. Adrenocorticotropic hormone receptor-blocking immunoglobulins in serum from patients with Addison's disease: a reexamination. Journal of Clinical Endocrinology and Metabolism $199377750-753$.

49 Furmaniak J, Talbot D, Reinwein D, Benker G, Creagh FM \& Smith B. Immunoprecipitation of human adrenal microsomal antigen. FEBS Letters 1988232 25-28.

50 Baumann-Antczak A, Wedlock N, Bednarek J, Kiso Y, Krishnan H, Fowler S, Rees Smith B \& Furmaniak J. Autoimmune Addison's disease and 21-hydroxylase. Lancet 1992340 429-430.

51 Bednarek J, Furmaniak J, Wedlock N, Kiso Y, Baumann-Antczak A, Fowler S et al. Steroid 21-hydroxylase is a major autoantigen involved in adult onset autoimmune Addison's disease. FEBS Letters 1992309 51-55.

52 Winqvist O, Karlsson FA \& Kämpe O. 21-Hydroxylase, a major autoantigen in idiopathic Addison's disease. Lancet 1992339 1559-1562.

53 Krohn K, Uibo R, Aavik E, Peterson P \& Savilahti K. Identification by molecular cloning of an autoantigen associated with Addison's disease as steroid $17 \alpha$-hydroxylase. Lancet 1992 $339770-773$.

54 Song Y-H, Connor E, Muir A, She JX, Zorovich B, Derovanesian D \& MacLaren N. Autoantibody epitope mapping of the 21hydroxylase antigen in autoimmune Addison's disease. Journal of Clinical Endocrinology and Metabolism 199478 1108-1112.

55 Uibo R, Aavik E, Peterson P, Perheentupa J, Aranko S, Pelkonen R \& Krohn KJE. Autoantibodies to cytochrome P450 enzymes p450scc, P450c17, and P450c21 in autoimmune polyglandular disease types I and II and in isolated Addison's disease. Journal of Clinical Endocrinology and Metabolism 199478 323-328.

56 Colls J, Betterle C, Volpato M, Rees Smith B \& Furmaniak J. A new immunoprecipitation assay for autoantibodies to steroid 21hydroxylase in Addison's disease. Clinical Chemistry 199541 375-380.

57 Peterson P, Uibo R, Peränen J \& Krohn K. Immunoprecipitation of steroidogenic enzyme autoantigens with autoimmune polyglandular syndrome type I (APS I) sera: further evidence for humoral immunity to P450c17 and P45021. Clinical and Experimental Immunology 1997107 335-340.

58 Chen S. Sawicka S, Betterle C. Powell M. Prentice L, Volpato M et al. Autoantibodies to steroidogenic enzymes in autoimmune polyglandular syndrome. Addison's disease and premature ovarian failure. Journal of Clinical Endocrinology and Metabolism 199681 1871-1876.

59 Tanaka H, Powell M, Chen S, Sawicka S, Asawa T, Betterle C, Volpato M, Rees Smith B \& Furmaniak J. Autoimmune adrenal diseases - a new sensitive assay for measurement of steroid 21hydroxylase autoantibodies. Journal of Clinical Endocrinology and Metabolism 199782 1440-1446.

60 Winqvist O, Söderbergh A \& Kämpe O. The autoimmune basis of adrenocortical destruction in Addison's disease. Molecular Medicine Today 19962 282-289.

61 Winqvist O, Gustafsson J, Rorsman F, Karlsson FA \& Kämpe O. Two different cytochrome $\mathrm{P} 450$ enzymes are the adrenal antigens in autoimmune polyendocrine syndrome type I and Addison's disease. Journal of Clinical Investigation 199392 2377-2385.

62 Rees Smith B \& Furmaniak J. Editorial: Adrenal and gonadal autoimmune diseases. Journal of Clinical Endocrinology and Metabolism 199580 1502-1505.

63 Arif S, Vallian S, Farzaneh F, Zanone MM, James SL, Pietropaolo M, Hettiarachchi S, Vergani D, Conway GS \& Peakman M. Identification of $3 \beta$-hydroxysteroid dehydrogenase as a novel target of steroid cell autoantibodies: association of autoantibodies with endocrine autoimmune disease. Journal of Clinical Endocrinology and Metabolism 199681 4439-4445.

64 Wedlock N, Asawa T, Baumann-Antczak A, Rees Smith B \& Furmanjak J. Autoimmune Addison's disease. Analysis of autoantibody binding sites on human steroid 21-hydroxylase. FEBS Letters 1993332 123-126.

65 Asawa T, Wedlock N, Baumann-Antczak A, Rees Smith B \& Furmanjak J. Naturally occurring mutations in human 21hydroxylase influence adrenal autoantibody binding. Journal of Clinical Endocrinology and Metabolism 199479 372-376.

66 Volpato M, Prentice L, Chen S, Betterle C, Rees Smith B \& Furmaniak J. A study of the epitopes on steroid 21-hydroxylase recognised by autoantibodies in patients with or without Addison's disease. Clinical and Experimental Immunology 1998 (In Press).

67 Miller WL. Molecular biology of steroid hormone synthesis. Endocrine Reviews 19889 295-318.

68 Furmaniak J, Kominami S, Asawa T, Wedlock N, Colls J \& Rees Smith B. Autoimmune Addison's disease. Evidence for a role of steroid 21-hydroxylase autoantibodies in adrenal insufficiency. Journal of Clinical Endocrinology and Metabolism 199479 15171521.

69 Boscaro M, Betterle C, Volpato M, Fallo F, Furmaniak J, Rees Smith B et al. Hormonal responses during various phases of autoimmune adrenal failure. No evidence for 21-hydroxylase enzyme activity inhibition in vivo. Journal of Clinical Endocrinology and Metabolism 199681 2801-2804.

70 Falorni A, Nikoshkov A, Laureti S, Grenbäck E, Hulting AL, Casucci G et al. High diagnostic accuracy for idiopathic Addison's disease with a sensitive radiobinding assay for autoantibodies against recombinant human 21-hydroxylase. Journal of Clinical Endocrinology and Metabolism $1995802752-$ 2755 . 
71 Falorni A, Laureti S, Nikoshkov A, Picchio ML, Hallengren B Vandewalle CL et al. 21-Hydroxylase autoantibodies in adult patients with endocrine autoimmune diseases are highly specific for Addison's disease. Clinical and Experimental Immunology 1997 107 341-346.

72 Bonifacio E, Boitard C, Gleichmann H, Shattock MA, Molenaar JML, Bottazzo GF et al. Assessment of precision, concordance, specificity, and sensitivity of islet cell antibody measurement in 41 assays. Diabetologia 199033 731-736.

73 Greenbaum CJ, Palmer JP, Kuglin B, Kolb H and participating laboratories. Insulin autoantibodies measured by radioimmunoassay methodology are more related to IDDM than those measured by enzyme-linked immunosorbent assay: results of the Fourth International Workshop on the Standardization of Insulin Autoantibody Measurement. Journal of Clinical Endocrinology and Metabolism 199274 1040-1044.

74 Schmidli RS, Colman PG, Bonifacio E, and participating laboratories. Disease sensitivity and specificity of 52 assays for glutamic acid decarboxylase antibodies. The Second International GADAb Workshop. Diabetes 199544 636-640.

75 Nerup J \& Bendixen G. Anti-adrenal cellular hypersensitivity in Addison's disease. 2. Correlation with clinical and serological findings. Clinical and Experimental Immunology $19695341-$ 353.

76 Volpè R. The role of autoimmunity in hypoendocrine and hyperendocrine function. Annals of Internal Medicine 197887 86-99.

77 Fairchild RS, Schimke RN \& Abdou NI. Immunoregulation abnormalities in familial Addison's disease. Journal of Clinical Endocrinology and Metabolism 198051 1074-1077.

78 Verghese MW, Ward FE \& Eisenbarth GS. Decreased suppressor cell activity in patients with polyglandular failure. Clinical Research 198028 270A.

79 Rabinowe SL, Jackson RA, Dluhy RG \& Williams GH. Ia-positive $\mathrm{T}$ lymphocytes in recently diagnosed idiopathic Addison's disease. American Journal of Medicine 198477 597-601.

80 Freeman M \& Weetman AP. T and B cell reactivity to adrenal antigens in autoimmune Addison's disease. Clinical and Experimental Immunology 199288 275-279.

81 Fujji Y, Kato N, Kito J, Asai J \& Yokochi T. Experimental autoimmune adrenalitis: a murine model for Addison's disease. Autoimmunity 199212 47-52.

82 Coulam CB. Premature gonadal failure. Fertility and Sterility 19826 645-655.

83 Coulam CB. Autoimmune ovarian failure. Seminars in Reproductive Endocrinology 19831 161-167.

84 Jones GS \& de Moraes-Ruehsen M. A new syndrome of amenorrhea in association with hypergonadotropism and apparently normal ovarian follicular apparatus. American Journal of Obstetrics and Gynecology 1969104 597-600.

85 Walfish PG, Gottesman IS, Shewchuk AB, Bain J, Hawe BS \& Farid NR. Association of premature ovarian failure with HLA antigens. Tissue Antigens 198321 168-169.

86 La Barbera AR, Miller MM, Ober C \& Rebar RW. Autoimmune etiology in premature ovarian failure. American Journal of Reproductive Immunology and Microbiology 198816 115-122.

87 Irvine WJ. Autoimmunity in endocrine disease. Recent Progress in Hormone Research 198036 509-556.

88 Coulam CB, Kempers R \& Randall RV. Premature ovarian failure: evidence for the autoimmune mechanisms. Fertility and Sterility $198136238-240$.

89 Gloor E \& Hurlimann J. Autoimmune oophoritis. American Journal of Clinical Pathology 198481 105-109.

90 Rabinowe SL, Berger MJ, Welk WR \& Dluhy RG. Lymphocyte dysfunction in autoimmune oophoritis: resumption of menses with corticosteroids. American Journal of Medicine 198681 347-350.

91 Sedmak DD, Hart WR \& Tubbs RR. Autoimmune oophoritis: a histological study involved ovaries with immunologic characterisation of the mononuclear infiltrate. International Journal of Gynecological Pathology 19876 73-81.
92 Scully RE, Mark EJ, MaNeely WF \& McNeely BU. Case record of the Massachussett's General Hospital, Case 46-1987. New England Journal of Medicine 1987317 1270-1278.

93 Wolfe CDA \& Stirling RW. Premature menopause associated with autoimmune oophoritis. Case report. British Journal of Obstetrics and Gynaecology 198895 630-632.

94 Biscotti CV, Hart WR \& Lucas JG. Cystic ovarian enlargment resulting from autoimmune oophoritis. Obstetrics and Gynecology $198974492-495$

95 Bannatyne P, Russell P \& Shearman RP. Autoimmune oophoritis: a clinicopathological assessment of 12 cases. International Journal of Gynecological Pathology 19909 191-207.

96 Lonsdale RN, Roberts PF \& Trowell JE. Autoimmune oophoritis associated with polycystic ovaries. Histopathology 1991 19 77-81.

97 Winqvist O. Gebre-Medhin G, Gustafsson J, Ritzén EM, Lundkvist $\hat{O}$, Karlsson FA et al. Identification of the main gonadal autoantigens in the patients with adrenal insufficiency and associated ovarian failure. Journal of Clinical Endocrinology and Metabolism 199580 1717-1723.

98 Rebar RW \& Cedars MI. Hypergonadotropic forms of amenorrhea in young women. Endocrinology and Metabolism Clinics of North America 199221 173-191.

99 Alper MM \& Garner PR. Premature ovarian failure: its relationship to autoimmune diseases. Obstetrics and Gynecology 198566 27-30.

100 Conway GS, Kaltsas G, Patel A, Davies MC \& Jacobs HS. Characterization of idiopathic premature ovarian failure. Fertility and Sterility $199665337-341$.

101 Kinch RAH, Plunkett ER, Smout MS \& Carr DH. Primary ovarian failure: a clinicopathological and cytogenetic study. American Journal of Obstetrics and Gynecology 196591 630-641.

102 Emparaire JC. Audebert A \& Greenblatt RB. Premature ovarian failure. American Journal of Obstetrics and Gynecology 1970108 445-449.

103 Zarate A, Karchmer S, Gomez E \& Castelazo-Ayala L. Premature menopause. American Journal of Obstetrics and Gynecology 1970 106 110-114.

104 Sharf M, Israeli I \& Graff G. The value of ovarian biopsy in the diagnosis and treatment of amenorrhea-related sterility. Obstetrics and Gynaecology 197239 89-94.

105 Starup J \& Sele V. Premature ovarian failure. Acta Obstetrica et Gynaecologica Scandinavica 197352 259-268.

106 Falk RJ. Euestrogenic ovarian failure. Fertility and Sterility 1977 28 502-503.

107 Duignan NM. Sex hormone levels and gonadotrophin release in premature ovarian failure. British Journal of Obstetrics and Gynaecology $197885862-867$.

108 Board JA, Redwine AO, Moncure CW, Frable WJ \& Taylor JR. Identification of differing etiologies of clinically diagnosed premature menopause. American Journal of Obstetrics and Gynecology 1979134 936-944.

109 Rebar RW, Eickson GF \& Yen SSC. Idiopathic premature ovarian failure: clinical and endocrine characteristics. Fertility and Sterility 198237 35-41.

110 Russell P, Bannatyne P, Shearman RP, Fraser IS \& Corbett P. Premature hypergonadotropic ovarian failure: clinicopathological study of 19 cases. International Journal of Pathology 19821 $185-201$.

111 Menon V, Logan Edwards R, Butt WR, Bluck M \& Lynch SS. Review of 59 patients with hypergonadotropic amenorrhea. British Journal of Obstetrics and Gynaecology 198491 63-66.

112 Aiman J \& Dmentek C. Premature ovarian failure. Obstetrics and Gynaecology 198566 9-14.

113 Miyaca T, Sato Y \& Takeuchi S. Implications of circulating autoantibodies and peripheral blood lymphocytes for the genesis of premature ovarian failure. Journal of Reproductive Immunology 198712 163-171.

114 Friedman CI, Gurgen-Varol F, Lucas J \& Neff J. Persistent progesterone production associated with autoimmune oophoritis. Journal of Reproductive Medicine 198732 193-196. 
115 Rebar WR \& Connolly HV. Clinical features of a young woman with hypergonadotropic amenorrhea. Fertility and Sterility 1990 53 804-810

116 Muechler EK, Huang K \& Schenk E. Autoimmunity in premature ovarian failure. International Journal of Fertility 19913699 103.

117 Moncayo H, Moncayo R, Benz R, Wolf A \& Lauritzen CH. Ovarian failure and autoimmunity. Detection of autoantibodies directed against both the unoccupied luteinizing hormone/ human chorionic gonadotropin receptor and the hormone receptor complex of bovine corpus luteum. Journal of Clinica Investigation 198984 1857-1865.

118 Wheatcroft NJ, Toogood AA, Li TC, Cooke ID \& Weetman AP. Detection of antibodies to ovarian antigens in women with premature ovarian failure. Clinical and Experimental Immunology $199496122-128$.

119 Luborsky JL, Visintin I, Boyers S, Asari T, Caldwell B \& DeCherney A. Ovarian antibody detected by immobilized antigen immunoassay in patients with premature ovarian failure. Journal of Clinical Endocrinology and Metabolism 1990 70 69-75.

120 Chiauzzi V, Cigorraga S, Escobar ME, Rivarola MA \& Charreau EH. Inhibition of follicle-stimulating hormone receptor binding by circulating immunoglobulins. Journal of Clinical Endocrinology and Metabolism 198254 1221-1228.

121 Escobar ME, Cigorraga SB, Chiauzzi VA, Charreau EH \& Rivarrola MA. Development of the gonadotrophic resistant ovary syndrome in myasthenia gravis: suggestion of similar autoimmune mechanisms. Acta Endocrinologica 198299 431436.

122 van Weisseenbruch MM, Hoek A, van Vliet-Bkeeker I \& Drexhage H. Evidence for existence of immunoglobulins that block ovarian granulosa cell growth in vitro. A putative role in resistent ovary syndrome? Journal of Clinical Endocrinology and Metabolism 199173 360-367.

123 Anasti JN, Flack MR, Froehlich J \& Nelson L. The use of human recombinant gonadotropin receptors to search for immunoglobulin G-mediated premature ovarian failure. Journal of Clinical Endocrinology and Metabolism 199580 824-828.

124 Edmonds M, Lamki L, Killinger D \& Volpe R. Autoimmune thyroiditis, adrenalitis and oophoritis. American Journal of Medicine $197354782-787$.

125 Rabinowe SL, Ravnikar VA, Dib SA. George KL \& Dluhy RG. Premature menopause: monoclonal antibody defined T lymphocytes abnormalities and anti-ovarian antibodies. Fertility and Sterility 198951 450-454.

126 Nelson LM, Kimzey L, Merriam G \& Fleisher TA. Increased peripheral T-lymphocyte activation in patients with karyotypically normal spontaneous premature ovarian failure. Fertility and Sterility $1991551082-1087$.

127 Wheatcroft NJ, Rogers CA, Metcalfe RA, Lenton EA, Cooke ID \& Weetman AP. Is subclinical ovarian failure an autoimmune disease? Human Reproduction 199712 244-249.

Received 9 June 1997

Accepted 4 August 1997 